УДК 579.64

DOI: 10.30679/2219-5335-2018-5-53-175-184

ИССЛЕДОВАНИЕ

БИОКОНТРОЛЬНЫХ СВОЙСТВ

БАКТЕРИЙ РОДА

BACILLUS В ОТНОШЕНИИ

ФИТОПАТОГЕНОВ МОРКОВИ

В ПРОЦЕССЕ ХРАНЕНИЯ

Першакова Татьяна Викторовна

д-р техн. наук, доцент

ведущий научный сотрудник

отдела хранения

и комплексной переработки

сельскохозяйственного сырья

Купин Григорий Анатольевич

канд. техн. наук

ст. научный сотрудник

отдела хранения

и комплексной переработки

сельскохозяйственного сырья

Михайлюта Лариса Васильевна

научный сотрудник

отдела хранения

и комплексной переработки

сельскохозяйственного сырья

Бабакина Мария Владимировна

мл. научный сотрудник

отдела хранения

и комплексной переработки

сельскохозяйственного сырья

Краснодарский научно-исследовательский институт хранения и переработки сельскохозяйственной продукции филиал ФГБНУ «Северо-Кавказский федеральный научный центр садоводства, виноградарства, виноделия», Краснодар, Россия

Егорова Зинаида Евгеньевна канд. техн. наук, доцент

Зеленкова Елена Николаевна ассистент

Учреждение образования «Белорусский государственный технологический университет», Минск, Беларусь
UDC 579.64

DOI: $10.30679 / 2219-5335-2018-5-53-175-184$

\section{STUDY OF BIOCONTROL PROPERTIES \\ OF BACILLUS BACTERIA GENUS \\ IN RELATION TO CARROT PHYTOPATHOGENS IN THE STORAGE PROCESS}

Pershakova Tatiana Viktorovna

D-r. Sci. Tech., Docent

Leading Research Associate

of Department of Storage

and Comprehensive Processing

of Agricultural Raw Materials

Kupin Grigoriy Anatolievich

Cand. Tech. Sci.

Senior Research Associate

of Department of Storage

and Comprehensive Processing

of Agricultural Raw Materials

Mikhaylyuta Larisa Vasilievna

Research Associate

of Department of Storage

and Comprehensive Processing

of Agricultural Raw Materials

Babakina Maria Vladimirovna

Junior Research Associate

of Department of Storage

and Comprehensive Processing

of Agricultural Raw Materials

Krasnodar Research Institute

of Agricultural Products Storage

and Processing - Branch of Federal

State Budgetary Scientific Institution

"North-Caucasus Federal Scientific Center

of Horticulture, Viticulture, Wine-making»,

Krasnodar, Russia

Egorova Zinaida Evgienevna

Cand. Tech. Sci., Docent

Zelenkova Elena Nikolaevna

Assistant

Educational institution

«Belarusian State

Technological University»,

Minsk, Belarus 
Потери продукции растениеводства в процессе хранения зависят от сортовых особенностей, системы защиты от вредителей и болезней, сроков и способов уборки, товарной обработки и способов подготовки к хранению и связаны с физиологическими, биохимическими и микробиологическими процессами, протекающими во время хранения. В связи с этим актуальным направлением исследований является разработка, модификация и совершенствование методов управления биохимическими и микробиологическими процессами длительного хранения продукции растениеводства.

Проведены исследования в области биологического контроля фитопатогенов возбудителей заболеваний моркови с использованием штаммов Bacillus subtilis. Показано, что наибольшую активность в отношении тестового набора патогенов, характерных для моркови, в экспериментах in vitro проявили штаммы Bacillus subtilis ИПМ 215 и ВKM B-2605D. Изучена динамика популяций фитопатогенов и штаммов-антагонистов в срезах корнеплодов моркови. Выявлено, что скорость роста популяции Bacillus subtilis на первом этапе хранения превышает скорость роста популяций Alternaria radicina и Erwinia carotovora. Через трое суток хранения динамика роста Bacillus subtilis снижается, что свидетельствует о целесообразности обработки корнеплодов препаратами Bacillus subtilis, которые на первом этапе хранения, в силу более интенсивного роста, создают конкуренцию в борьбе за питательные вещества. Кроме того, продукты жизнедеятельности Bacillus subtilis являются эффективными ингибиторами фитопатогенов.

По итогам проведенных исследований установлено, что обработка корнеплодов Bacillus subtilis влияет на степень развития заболеваний, вызванных Alternaria radicina и Erwinia carotovora, что позволяет рассматривать исследуемые штаммы Bacillus subtilis как перспективные
The losses of crop production during storage depend on variety characteristics, the system of protection against vermins and diseases, terms and methods of harvesting, commodity processing and storage preparation methods and are associated with physiological, biochemical and microbiological processes occurring during storage. In connection with this, the current direction of research is the development, modification and improvement of methods for managing the biochemical and microbiological processes of long-term storage of crop production. Research has been carried out in the field of biological control of phytopathogens causative agents of carrot diseases using strains of Bacillus subtilis. It is shown that the most active in relation to the test set of pathogens characteristic for carrots in vitro experiments were strains of Bacillus subtilis IPM 215 and VKM B-2605D. The dynamics of populations of phytopathogens and antagonist strains in the sections of carrot roots was studied. It is revealed that the rate of growth of the Bacillus subtilis population in the first stage of storage exceeds the growth rate of the populations Alternaria radicina and Erwinia carotovora. After three days of storage, the growth dynamics of Bacillus subtilis decreases, which indicates the expediency of processing root crops with Bacillus subtilis preparations, which, due to more intensive growth, creates the competition in the struggle for nutrients during the first stage of storage. In addition, the products of the life of Bacillus subtilis are effective inhibitors of phytopathogens.

As a result of carried out research it is established that the treatment of root crops of Bacillus subtilis influences the degree of development of diseases caused by Alternaria radicina and Erwinia carotovora that allows to consider the studied strains of Bacillus subtilis as promising 
для биологического контроля заболеваний, for the biological control of diseases вызываемых фитопатогенными caused by phytopathogenic микроорганизмами в процессе хранения корнеплодов моркови. microorganisms during storage of root crops of carrots.

Ключевые слова: ВACILLUS SUBTILIS, БИОКОНТРОЛЬ, ФИТОПАТОГЕНЫ, МОРКОВЬ, ХРАНЕНИЕ, ЗАБОЛЕВАЕМОСТЬ

Key words: BACILLUS SUBTILIS, BIOCONTROL, PHYTOPATHOGENS, CARROT, STORAGE, MORBIDITY

Bведение. Предотвращение потерь сельскохозяйственной продукции - важнейший аспект продовольственной безопасности. Потери продукции растениеводства в процессе хранения зависят от сортовых особенностей, системы защиты от вредителей и болезней, сроков и способов уборки, товарной обработки и способов подготовки к хранению и связаны с физиологическими, биохимическими и микробиологическими процессами, протекающими во время хранения.

В связи с этим актуальным направлением исследований является «Разработка, модификация и совершенствование методов управления биохимическими и микробиологическими процессами длительного хранения», в рамках которого проводится исследование микоцидных и микостатических свойств бактерий-антагонистов по отношению к основным возбудителям инфекционных заболеваний растительной продукции.

Морковь - один из наиболее сложных в хранении вид овощей. Физиологические особенности этого корнеплода требуют обеспечения высокой влажности в процессе хранения, при этом высокая влажность провоцирует интенсивный рост патогенной микрофлоры. Поэтому актуальными исследования в области биологического контроля фитопатогенов - возбудителей наиболее распространенных заболеваний моркови. В частности, была проведена оценка антагонистической эффективности бактериальных штаммов Bacillus subtilis по отношению к фитопатогенам моркови, вызывающим белую и черную гнили, мокрую бактериальную гниль в опытах in vitro и in vivo. 
Плодоводство и виноградарство Юга России № 53(05), 2018 г.

На основании проведенного аналитического обзора отечественной и зарубежной научно-технической литературы и патентной информации были установлены наиболее эффективные антагонисты фитопатогенов, вызвывающих заболевания овощных культур. Проведена сравнительная оценка биоконтрольной эффективности штаммов Bacillus subtilis по отношению к фитопатогенам, вызывающим заболевания моркови. Изучены динамика популяций фитопатогенов и штаммов-антагонистов в срезах корнеплодов моркови при различных температурах хранения, а также влияние Bacillus subtilis на диаметр поражения, вызываемого фитопатогенами.

Проведенный обзор показал, что бактерии рода Bacillus обладают преимуществами по сравнению с другими за счет способности продуцировать широкий спектр антибиотиков. Известны исследования российских и зарубежных ученых, подтверждающих биоконтрольную эффективность штаммов Bacillus subtilis в отношении фитопатогенов родов Fusarium, Sclerotinia, Rhizopus Botrytis и снижение заболеваемости в процессе хранения редиса, томатов, моркови, картофеля, бобовых культур [1-9].

Несмотря на значительное количество исследований остается не изученной биоконтрольная эффективность ряда штаммов Bacillus subtilis продуцентов отечественных биопрепаратов по отношению к фитопатогенам, вызывающим болезни моркови в процессе хранения.

Объекты и методы исследований. Исследования проводили с корнеплодами моркови сорта Абако, выращенной в Динском районе Краснодарского края. Грибковые патогены Sclerotinia sclerotiorum и Alternaria radicina, вызывающие белую и черную гниль, Erwinia carotovora - возбудитель мокрой бактериальной гнили были выделены из пораженных корнеплодов моркови. В качестве штаммов антагонистов использовали штаммы Bacillus subtilis, являющиеся основой биологических препаратов российского производства. 
Плодоводство и виноградарство Юга России № 53(05), 2018 г.

Исследования in vitro антагонистических свойств штаммов бактерий рода Bacillus subtilis в отношении фитопатогенных микроорганизмов осуществляли методом агаровых блоков. Динамику развития популяций исследуемых штаммов исследовали в срезах корнеплодов при температурах $+25{ }^{\circ} \mathrm{C}$ и при $+2{ }^{\circ} \mathrm{C}$.

Обсужљение результатов. В таблице представлены данные, характеризующие антагонистическую активность исследуемых штаммов Bacillus subtilis. Из приведенных данных можно сделать вывод о том, что все исследуемые штаммы в большей или меньшей степени вызывают задержку роста исследуемых патогенов.

Наибольшую активность в отношении тестового набора патогенов, характерных для моркови, в экспериментах in vitro проявили штаммы Bacillus subtilis ИПМ 215 и ВКМ В-2605 D.

Антагонистическая активность исследуемых штаммов Bacillus subtilis

\begin{tabular}{|l|r|c|c|c|c|}
\hline \multirow{2}{*}{ Патоген } & \multicolumn{5}{|c|}{ Штамм (биопрепарат)/ зона задержки роста, мм } \\
\cline { 2 - 7 } & $\begin{array}{c}\text { Ч-13 } \\
\text { (Экстрасол) }\end{array}$ & $\begin{array}{c}\text { В-10 ВИЗР } \\
\text { (Алирин) }\end{array}$ & $\begin{array}{c}\text { ИПМ 215 } \\
\text { (Бактофит) }\end{array}$ & $\begin{array}{c}\text { ВКМ В-2605 D } \\
\text { (Витаплан) }\end{array}$ & $\begin{array}{c}\text { М-22 ВИЗР } \\
\text { (Гамаир) }\end{array}$ \\
\hline $\begin{array}{l}\text { Sclerotinia } \\
\text { sclerotiorum }\end{array}$ & 2,1 & 1,3 & $\mathbf{2 , 3}$ & $\mathbf{2 , 2}$ & 1,7 \\
\hline $\begin{array}{l}\text { Alternaria } \\
\text { radicina }\end{array}$ & 2,0 & 1,4 & $\mathbf{2 , 7}$ & $\mathbf{2 , 6}$ & 2,1 \\
\hline $\begin{array}{l}\text { Erwinia } \\
\text { carotovora }\end{array}$ & 3,0 & 1,8 & $\mathbf{3 , 3}$ & $\mathbf{3 , 2}$ & 1,7 \\
\hline
\end{tabular}

На следующем этапе исследований был проведен сравнительный анализ динамики роста популяции исследуемых штаммов Bacillus subtilis и фитопатогенов, вызывающих заболевания моркови в зависимости от температуры хранения. Результаты исследования динамики популяции фитопатогенов и Bacillus subtilis (штамм ИПМ 215) в срезах корнеплодов моркови при $+25{ }^{\circ} \mathrm{C}$ в течение 7 суток хранения приведены на рис. 1 . 


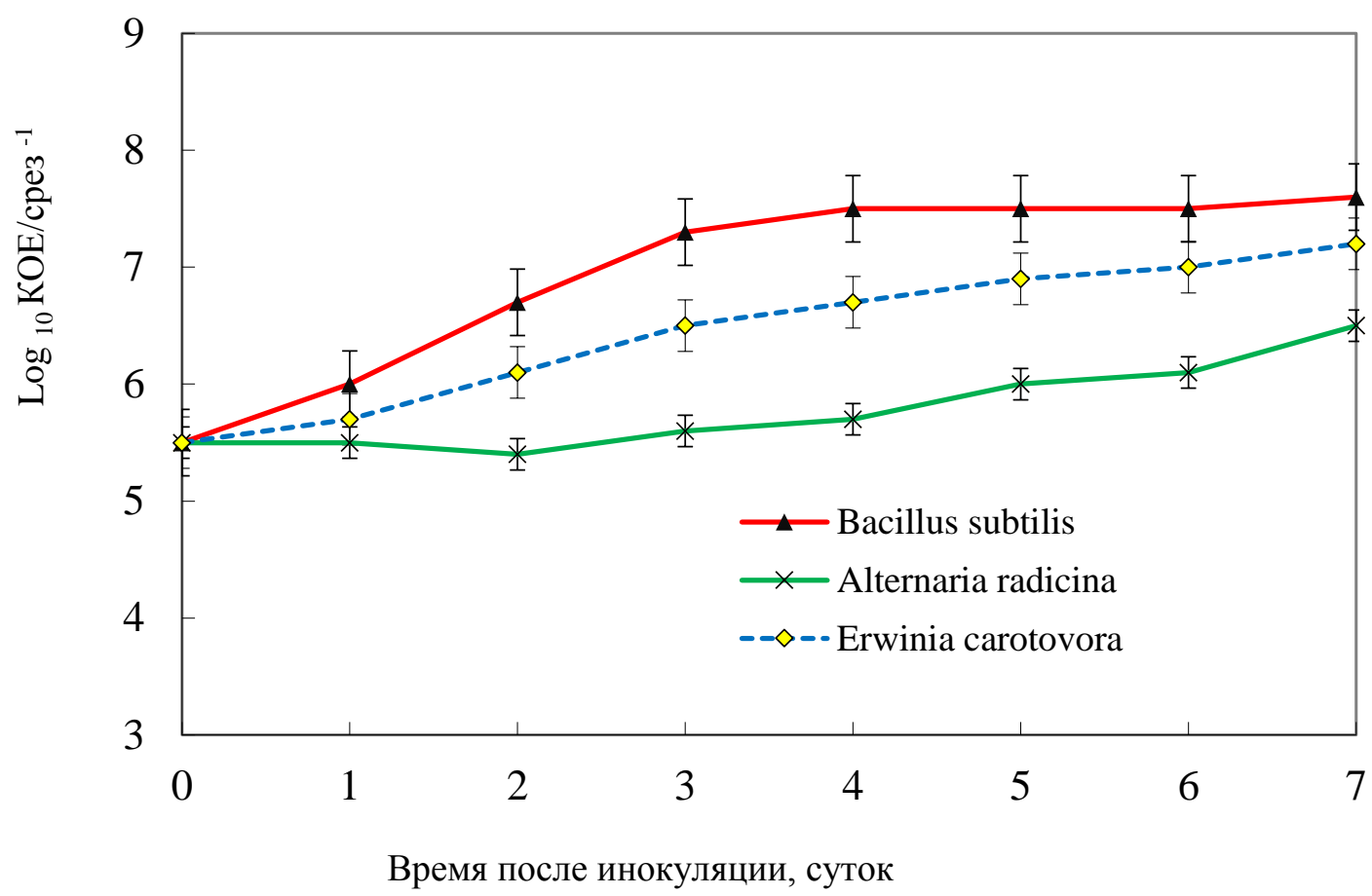

Рис.1. Динамика популяции фитопатогенов и Bacillus subtilis (штамм ИПМ 215) в срезах корнеплодов моркови при $+25^{\circ} \mathrm{C}$ в течение 7 суток хранения

На основании полученных данных можно сделать вывод о том, что при температуре $+25^{\circ} \mathrm{C}$ скорость роста популяции Bacillus subtilis на первом этапе хранения превышает скорость роста популяций Alternaria radicina и Erwinia carotovora. Через трое суток хранения динамика роста Bacillus subtilis снижается.

Данный факт позволяет предполагать целесообразность обработки корнеплодов Bacillus subtilis, который на первом этапе хранения, в силу более интенсивного роста, создает конкуренцию в борьбе за питательные вещества. Кроме того, продукты жизнедеятельности Bacillus subtilis являются эффективными ингибиторами фитопатогенов.

Динамика популяции фитопатогенов и Bacillus subtilis (штамм ИПМ $215)$ в срезах корнеплодов моркови при $+2{ }^{\circ} \mathrm{C}$ в течение 14 суток хранения приведена на рис. 2. 


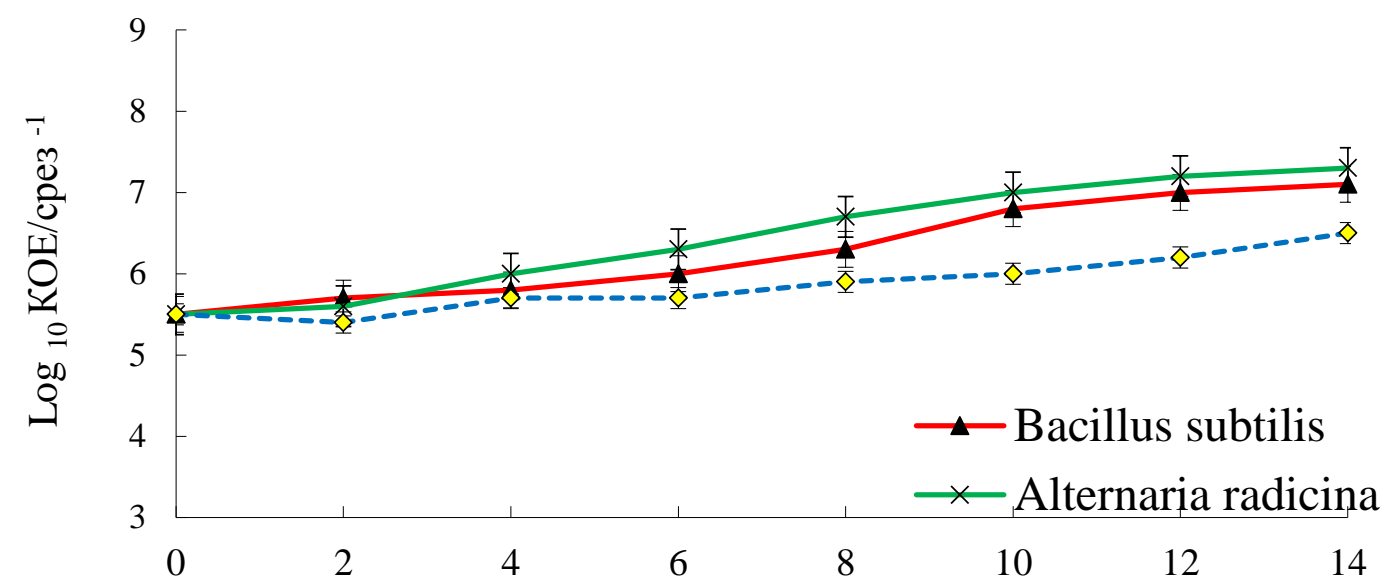

Время после инокуляции, суток

Рис. 2. Динамика популяции фитопатогенов и Bacillus subtilis (штамм ИПМ 215) в срезах корнеплодов моркови при $+2{ }^{\circ} \mathrm{C}$ в течение 14 суток хранения

Данные, представленные на рис. 2, свидетельствуют о том, что при температуре $+2{ }^{\circ} \mathrm{C}$ на первом этапе хранения количество клеток Bacillus subtilis изменяется незначительно, но после 7 суток хранения происходит адаптация, и популяция начинает увеличиваться. К концу 14 суток хранения величина популяции Bacillus subtilis превышает величину популяции Erwinia carotovora и практически сравнивается с популяцией Alternaria radicina.

Полученные данные позволяют сделать вывод о том, что для использования препаратов на основе Bacillus subtilis в целях ингибирования заболеваний, вызываемых фитопатогенами моркови, целесообразна обработка Bacillus subtilis при температуре $+25^{\circ} \mathrm{C}$, выдержка в течение 2 суток при данной температуре и последующее охлаждение до температуры $+2{ }^{\circ} \mathrm{C}$.

На следующем этапе исследований проверяли гипотезу об ингибировании заболеваний, вызываемых фитопатогенами Erwinia carotovora и Alternaria radicina, при обработке моркови Bacillus subtilis в процессе хранения. Изучалось влияние Bacillus subtilis (штамм ИПМ 215) на диаметр поражения, вызываемого фитопатогенами, в зависимости от температуры через 7,14 и 28 суток хранения (рис. 3,4 ). 
Приведенные на рис. 1 и 2 данные позволяют сделать вывод о том, что через 7,14 и 28 суток хранения при температурах $+25^{\circ} \mathrm{C}$ и $+2{ }^{\circ} \mathrm{C}$ средний диаметр поражения у корнеплодов моркови, обработанных Bacillus subtilis, был ниже как для образцов зараженных Alternaria radicina, так и для образцов, зараженных Erwinia carotovora.

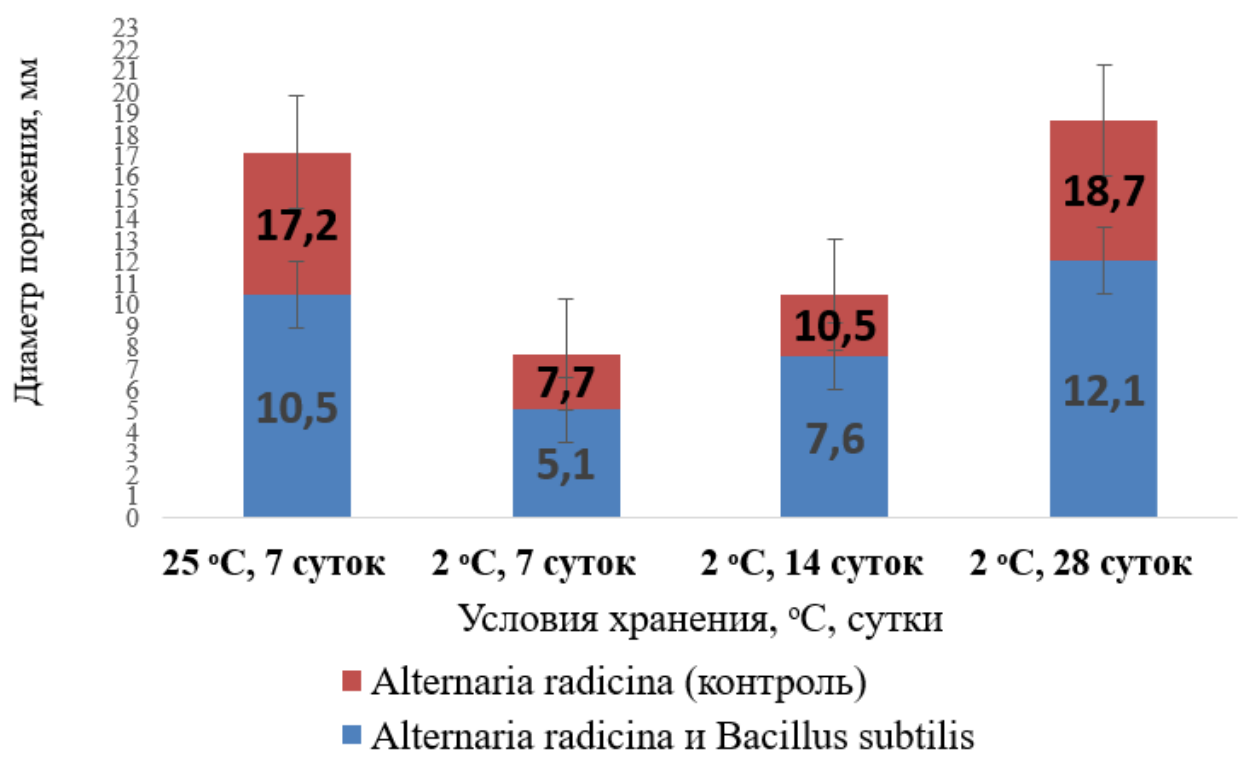

Рис. 3. Влияние Bacillus subtilis (штамм ИПМ 215) на диаметр поражения, вызываемого Alternaria radicina, в зависимости от температуры через 7,14 и 28 суток хранения

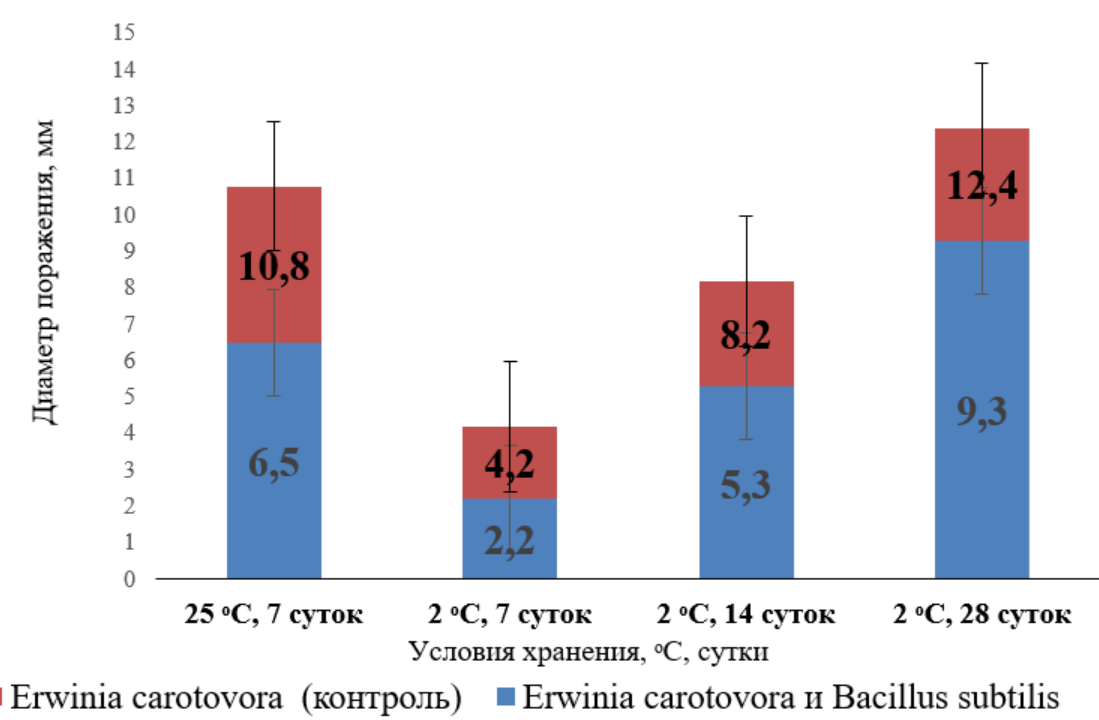

Рис. 4. Влияние Bacillus subtilis (штамм ИПМ 215) на диаметр поражения, вызываемого Erwinia carotovora, в зависимости от температуры через 7,14 и 28 суток хранения 
Плодоводство и виноградарство Юга России № 53(05), 2018 г.

Bbыводы. На основании проведенных исследований установлены антагонистические свойства и выявлены наиболее эффективные штаммы бактерий Bacillus subtilis в отношении фитопатогенов моркови. Установлено, что обработка корнеплодов Bacillus subtilis влияет на степень развития заболеваний, вызванных Alternaria radicina, и Erwinia carotovora, что позволяет рассматривать исследуемые штаммы Bacillus subtilis как перспективные для биологического контроля заболеваний, вызываемых фитопатогенными микроорганизмами в процессе хранения корнеплодов моркови.

Проведенные исследования позволяют решать научно-практические задачи «Оптимизации способов управления биохимическими и микробиологическими процессами длительного хранения», в частности разработать технологии подготовки корнеплодов моркови к длительному хранению, обеспечивающие снижение потерь, стабилизацию качества и максимальное сохранение биологически активных веществ в процессе хранения.

\section{Литература}

1. M.Oliveira, J.Usall, I.Viñas, M.Anguera, F.Gatius, M.Abadias, 2010. Microbiological quality of fresh lettuce from organic and conventional production. Food Microbiology 27 (5): 679-684. Date Views 2.03.2018 https://doi.org/10.1016/j.fm.2010.03.008.

2. Ioannis S. Arvanitoyannis, Alexandros Ch. Stratakos, 2010. Chapter 12 - Irradiation of Fruits and Vegetables. Irradiation of Food Commodities, 2010: 467-535. Academic press. Date Views 2.03.2018 https://doi.org/10.1016/B978-0-12-374718-1.10012-4.

3. Першакова, Т.В. Способы обеспечения стабильного качества растительного сырья в процессе хранения с применением биопрепаратов / Т.В. Першакова, В.В. Лисовой, Г.А. Купин, Е.Ю. Панасенко, Е.П. Викторова // Политематический научный журнал Кубанского государственного аграрного университета (Научный журнал КубГАУ) [Электронный ресурс]. - 2016. - № 03 (117). Режим доступа: http://ej.kubagro.ru/2016/02/pdf/14.pdf.

4. L. Cavaglieri, J. Orlando, M.I. Rodriguez, S. Chulze, M. Etcheverry, 2005. Biocontrol of Bacillus subtilis against Fusarium verticillioides in vitro and at the maize root level. Research in Microbiology, 156 (5-6), 748-754. Date Views 1.03.2018 https://doi.org/10.1016/j.resmic.2005.03.001.

5. Anna On, Francis Wong, Queenie Ko, Russell J. Tweddell, Hani Antounb, Tyler J. Avis, 2015. Antifungal effects of compost tea microorganisms on tomato pathogens. Biological Control, 80, 63-69. Date Views 1.03.2018 https://doi.org/10.1016 /j.biocontrol.2014.09.017.

6. Zamir K.Punja, Gina Rodriguez, Ananchanok Tirajoh, 2016. Effects of Bacillus subtilis strain QST 713 and storage temperatures on post-harvest disease development on greenhouse tomatoes. Crop Protection, 84, 98-104. Date Views 1.03.2018 
7. S. Rao, M. Kamalnath. R. Umamaheswari, R. Rajinikanth, P. Prabu, K. Priti, G.N. Grace, M.K. Chaya, C. Gopalakrishnan, 2017. Bacillus subtilis IIHR BS-2 enriched vermicompost controls root knot nematode and soft rot disease complex in carrot. Scientia Horticulturae, 218, 56-62. Date Views 1.03.2018

8. Haiyan Fan. Jinjiang Ru, Yuanyuan Zhang, Qi Wang, Yan Li, 2017. Fengycin produced by Bacillus subtilis 9407 plays a major role in the biocontrol of apple ring rot disease, 199, 89-97. Date Views 1.03.2018 https://doi.org/10.1016/j.micres.2017.03.004

9. Saoussen Ben Khedher, Olfa Kilani-Feki, Mouna Dammak, Hayfa JabnounKhiareddine, Mejda Daami-Remadi, Slim Tounsi. Efficacy of Bacillus subtilis V26 as a biological control agent against Rhizoctonia solani on potato. Comptes Rendus Biologies, 338 (12), 784-792. Date Views 4.03.2018 https://doi.org/10.1016/j.crvi.2015.09.005.

\section{References}

1. M.Oliveira, J.Usall, I.Viñas, M.Anguera, F.Gatius, M.Abadias, 2010. Microbiological quality of fresh lettuce from organic and conventional produc-tion. Food Microbiology 27 (5): 679-684. Date Views 2.03.2018 https://doi.org/10.1016/j.fm.2010.03.008.

2. Ioannis S. Arvanitoyannis, Alexandros Ch. Stratakos, 2010. Chap-ter 12 - Irradiation of Fruits and Vegetables. Irradiation of Food Commodi-ties, 2010: 467-535. Academic press. Date Views 2.03.2018 https://doi.org/10.1016/B978-0-12-374718-1.10012-4.

3. Pershakova, T.V. Sposoby obespecheniya stabil'nogo kachestva rastitel'nogo syr'ya $\mathrm{v}$ processe hraneniya s primeneniem biopreparatov / T.V. Pershakova, V.V. Lisovoj, G.A. Kupin, E.Yu. Panasenko, E.P. Vik-torova // Politematicheskij nauchnyj zhurnal Kubanskogo gosudarstven-nogo agrarnogo universiteta (Nauchnyj zhurnal KubGAU) [Elektronnyj resurs]. $\quad-\quad 2016 . \quad-\quad$ № 03 (117). Rezhim dostupa: http://ej.kubagro.ru/2016/02/pdf/14.pdf.

4. L. Cavaglieri, J. Orlando, M.I. Rodriguez, S. Chulze, M. Etcheverry, 2005. Biocontrol of Bacillus subtilis against Fusarium verticillioides in vitro and at the maize root level. Research in Microbiology, 156 (5-6), 748-754. Date Views 1.03.2018 https://doi.org/10.1016/j.resmic.2005.03.001.

5. Anna On, Francis Wong, Queenie Ko, Russell J. Tweddell, Hani Antounb, Tyler J. Avis, 2015. Antifungal effects of compost tea microorgan-isms on tomato pathogens. Biological Control, 80, 63-69. Date Views 1.03.2018 https://doi.org/10.1016/ j.biocontrol.2014.09.017.

6. Zamir K.Punja, Gina Rodriguez, Ananchanok Tirajoh, 2016. Effects of Bacillus subtilis strain QST 713 and storage temperatures on post-harvest disease development on greenhouse tomatoes. Crop Protection, 84, 98-104. Date Views 1.03.2018

7. S. Rao, M. Kamalnath. R. Umamaheswari, R. Rajinikanth, P. Prabu, K. Priti, G.N. Grace, M.K. Chaya, C. Gopalakrishnan, 2017. Bacillus subtilis IIHR BS-2 enriched vermicompost controls root knot nematode and soft rot disease complex in carrot. Scientia Horticulturae, 218, 56-62. Date Views 1.03.2018

8. Haiyan Fan. Jinjiang Ru, Yuanyuan Zhang, Qi Wang, Yan Li, 2017. Fengycin produced by Bacillus subtilis 9407 plays a major role in the bio-control of apple ring rot disease, 199, 89-97. Date Views 1.03.2018 https://doi.org/10.1016/j.micres.2017.03.004

9. Saoussen Ben Khedher, Olfa Kilani-Feki, Mouna Dammak, Hayfa JabnounKhiareddine, Mejda Daami-Remadi, Slim Tounsi. Efficacy of Bacil-lus subtilis V26 as a biological control agent against Rhizoctonia solani on potato. Comptes Rendus Biologies, 338 (12), 784-792. Date Views 4.03.2018 https://doi.org/10.1016/j.crvi.2015.09.005. 